\title{
Androgens have antiresorptive effects on trabecular disuse osteopenia independent from muscle atrophy
}

\author{
Michaël R. Laurent, ${ }^{\text {a,b,c }}$ Ferran Jardí, ${ }^{d}$ Vanessa Dubois, ${ }^{a 1}$ Dieter Schollaert, ${ }^{a}$ Rougin \\ Khalil, ${ }^{d}$ Evelien Gielen, ${ }^{b, c}$ Geert Carmeliet, ${ }^{d}$ Frank Claessens ${ }^{a}{ }^{*}$, Dirk \\ Vanderschueren, ${ }^{d *}$ \\ ${ }^{*}=$ equal contribution \\ ${ }^{a}$ Laboratory of Molecular Endocrinology, Department of Cellular and Molecular Medicine, KU Leuven, \\ Herestraat 49 PO box 901, 3000 Leuven, Leuven, Belgium \\ ${ }^{\mathrm{b}}$ Gerontology and Geriatrics, Department of Clinical and Experimental Medicine, KU Leuven, \\ Herestraat 49 PO box 7003, 3000 Leuven, Leuven, Belgium \\ ${ }^{\mathrm{c}}$ Center for Metabolic Bone Diseases, University Hospitals Leuven, Herestraat 49, 3000 Leuven, \\ Belgium \\ ${ }^{d}$ Clinical and Experimental Endocrinology, Department of Cellular and Molecular Medicine, KU \\ Leuven, Herestraat 49 PO box 902, 3000 Leuven, Leuven, Belgium
}

\section{E-mail addresses:}

michael.laurent@kuleuven.be ; ferran.jardi@kuleuven.be ; vanessa.dubois@inserm.fr ; dieter.schollaert@kuleuven.be ; rougin.khalil@kuleuven.be ; evelien.gielen@uzleuven.be ; geert.carmeliet@kuleuven.be ; frank.claessens@kuleuven.be ; dirk.vanderschueren@uzleuven.be

\section{Conflicts of interest: none.}

\section{Corresponding author:}

Michaël R. Laurent, MD

Department of Cellular and Molecular Medicine, KU Leuven

Herestraat $49 \mathrm{PO}$ box 901

3000 Leuven, BELGIUM

michael.laurent@kuleuven.be

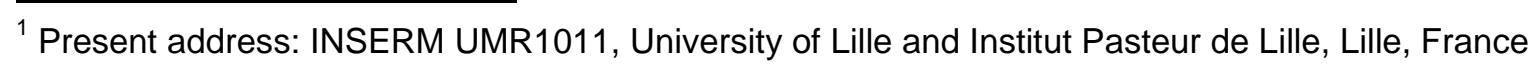




\section{Abstract}

Aging hypogonadal men are at increased risk of osteoporosis and sarcopenia. Testosterone is a potentially appealing strategy to prevent simultaneous bone and muscle loss. The androgen receptor (AR) mediates antiresorptive effects on trabecular bone via osteoblast-lineage cells, as well as muscle-anabolic actions. Sex steroids also modify the skeletal response to mechanical loading. However, it is unclear whether the effects of androgens on bone remain effective independent of mechanical stimulation or rather require indirect androgen effects via muscle. This study aims to characterize the effects and underlying mechanisms of androgens on disuse osteosarcopenia. Adult male mice received a unilateral botulinum toxin (BTx) injection, and underwent sham surgery or orchidectomy $(\mathrm{ORX})$ without or with testosterone $(\mathrm{ORX}+\mathrm{T})$ or dihydrotestosterone $(\mathrm{ORX}+\mathrm{DHT})$ replacement. Compared to the contralateral internal control hindlimb, acute trabecular number and bone volume loss was increased by ORX and partially prevented DHT. T was more efficient and increased BV/TV in both hindlimbs over sham values, although it did not reduce the detrimental effect of BTx. Both androgens and BTx regulated trabecular osteoclast surface as well as tartrate-resistant acid phosphatase expression. Androgens also prevented BTx-induced body weight loss but did not significantly influence paralysis or muscle atrophy. BTx and ORX both reduced cortical thickness via endosteal expansion, which was prevented by T but not DHT. In long-term follow-up, the residual trabecular bone volume deficit in sham-BTx hindlimbs was prevented by DHT but T restored it more efficiently to pre-treatment levels. Conditional AR deletion in late osteoblasts and osteocytes or in the satellite cell lineage increased age-related trabecular bone loss in both hindlimbs without influencing the effect of BTx on trabecular osteopenia. We conclude that androgens have antiresorptive effects on trabecular disuse osteopenia which do not require AR actions on bone via muscle or via osteocytes.

\section{Keywords}

Androgen receptor ; Androgens ; Conditional knock-out mice ; Disuse osteoporosis ; Muscle ; Testosterone 


\section{Introduction}

Androgens are sex steroid hormones which act via the androgen receptor (AR) on bone and muscle cells [1, 2]. Testosterone $(T)$, the principal circulating androgen, can activate AR directly or following conversion to dihydrotestosterone (DHT). T can also be aromatized into estrogens (whereas DHT cannot) to regulate male bone homeostasis, mainly via estrogen receptor $\alpha(E R \alpha)[2,3]$. Over the last decade, the target cells of androgen actions on the musculoskeletal system have been investigated in AR knock-out (ARKO) mouse models using Cre/LoxP technology $[4,5]$. These studies have shown that the antiresorptive effects of androgens on trabecular bone as seen in ubiquitous ARKO mice are recapitulated by conditional deletion of $A R$ in the early osteoblast lineage, with some contribution from AR in late osteoblasts and osteocytes but not from AR in osteoclasts [3, 6-10]. The effects of T on endosteal resorption on the other hand are mediated via aromatization while the target cell(s) for androgen actions on periosteal bone formation remains elusive $[2,3,11]$.

The anabolic effects of androgens on muscle are well known in humans [12, 13]. There is considerable interest in the use of T therapy in aging men, although this carries a risk of side-effects such as cardiovascular events, polycythemia and stimulation of prostate tissue. There is also growing realization that muscle may have indirect effects on bone via muscle-bone interactions $[1,14]$. Because androgens like T have effects on both muscle and bone, they are theoretically an appealing strategy for the combination of disuse osteoporosis and sarcopenia [14, 15]. Furthermore, low serum T concentrations are often seen in situations of acute disuse [16-21]. However, whether muscle AR has direct effects on bone has not yet been reported. A better understanding of the target cells and underlying mechanisms of the beneficial effects of androgens is required to inform their appropriate use and to design alternative therapies which avoid their potential side-effects e.g. on the prostate and cardiovascular system [22, 23].

Botulinum toxin (BTx) injection has been developed as an interesting preclinical model to study muscle-bone interactions [24-26]. By inhibiting specific proteins involved in vesicle fusion, BTx prevents presynaptic release of acetylcholine at the neuromuscular junction. Intramuscular injection of low BTx doses in rodents produces a local, transient (about 2-3 weeks) muscle paralysis with rapid trabecular bone resorption, followed by a partial recovery phase with residual unilateral osteosarcopenia [27-29]. The resultant cortical bone loss in contrast is more spatially heterogeneous [30-32]. Previous studies have suggested that androgens may have a beneficial effect on disuse 
osteoporosis [16, 20, 33-36]. Importantly, sex steroids and their receptors are also known to influence mechanoresponsivity [14]. Androgens specifically have been reported to inhibit the osteogenic response to mechanical loading $[37,38]$. Whether androgens also inhibit disuse osteoporosis via direct effects on bone or indirectly by preventing muscle atrophy remains unclear. We hypothesized that androgens would exert an anti-remodeling effect which would blunt the catabolic effects of disuse (which is beneficial), while at the same time they have been shown to reduce the osteogenic gains from mechanical loading (which is not a beneficial effect) [37, 38].

Thus, the aim of this study was to investigate the target cells and mechanisms of AR actions in disuse osteoporosis. For this purpose, we performed unilateral hindlimb i.m. BTx injections in sham-operated or castrated mice given placebo, $\mathrm{T}$ or $\mathrm{DHT}$ replacement, or in mice with conditional deletion of the AR in late osteoblasts and osteocytes or in the satellite cell lineage.

\section{Materials and methods}

\subsection{Animals}

All mice were group-housed (3-5 animals/cage) in conventional animal facilities. Sixteen-week-old male C57BL6/J mice were purchased from Janvier Labs (Le Genest-Saint-Isle, France). Male mice heterozygous for a cyclization recombinase driven by the dentin matrix protein 1 promoter (Dmp1-Cre, a kind gift from dr. L. Bonewald, University of Missouri-Kansas City, Kansas City, MO-KS, USA) were bred with female mice homozygous for a floxed AR exon 2 allelle [39] to generate male $\mathrm{AR}^{\text {flox/Y }} \mathrm{Cre}^{+/-}$ and $\mathrm{AR}^{\mathrm{flox} / \mathrm{Y}} \mathrm{Cre}^{-/-}$control littermates as described [8]. Mice with conditional knock-out of $\mathrm{AR}$ in the satellite cell lineage were obtained by a similar breeding scheme using MyoD-iCre (generously donated by dr. D. Goldhamer, University of Connecticut, Storss, CT, USA) as reported [40, 41]. All mutant mice have been backcrossed onto a C57BL6/J genetic background and were genotyped as previously described [8, 40, 41]. The KU Leuven Ethical Committee for Animal Experimentation approved all procedures (P190/2011) and mice were treated in accordance with current Belgian national regulations for Animal Welfare and the 2010/63/EU directive.

\subsection{Experimental design and procedures}

Mice were operated under isoflurane anesthesia. At 16 weeks of age, mice received a unilateral hindlimb injection of botulinum toxin type A (Botox®, Allergan, Irvine, CA, USA) [24], 2 U/100 g body weight in $30 \mu \mathrm{L}$ phosphate-buffered saline (PBS), divided over the quadriceps (15 $\mu \mathrm{L})$, hamstrings (10 
$\mu \mathrm{L}$ ) and calf muscles (5 $\mu \mathrm{L}$ ) [27] using a customized microsyringe (SGE Analytical Sciences, Bellefonte, PA, USA). Since the systemic effects of this treatment have been well characterized [25], we used the contralateral non-injected leg as an internal control. Muscle paralysis was quantified using the previously described digit abduction score [42] and the gait function inventory system [25]. The latter system involves a 0-2 point score on five items (total score range 0-10): (i) hindlimb abduction during tail suspension, (ii) toe extension during sitting, (iii) use of hindlimb during level walking, (iv) use of hindlimb during two legged stance, and (v) use of hindlimb during climbing [25] (Supplemental Video 1). Mice were provided energy-dense pellets and hydrogel on the bottom of the cage to facilitate eating and drinking during the first week post-injection.

Mice were further divided into four experimental groups: sham surgery + placebo treatment (sham), orchidectomy + placebo $(\mathrm{ORX}), \mathrm{ORX}+\mathrm{T}$ or ORX + DHT. Sham surgery or ORX were performed via a suprapubic incision. Implants of medical-grade silicone tubing (Silclear, Degania Medical, Degania, Israel) sealed with medical adhesive silicone (Silastic, Biesterfeld, Germany) were implanted in the nuchal region, either empty (placebo) or filled with T (Serva, Heidelberg, Germany) or DHT (SigmaAldrich, St. Louis, MO, USA), allowing continuous hormone release as described previously [38]. The resultant androgenic activity was assessed ex vivo by the wet weight of the androgen-sensitive seminal vesicles and levator ani/bulbocavernosus (LA/BC) muscle complex [41, 43].

To study the effects of androgens on acute disuse osteoporosis as well as during the recovery phase, hindlimb muscle and bone were imaged by in vivo microcomputed tomography (microCT) at baseline, after 3 weeks and at 4-weekly intervals thereafter for up to 7 or 19 weeks as indicated. Other mice were euthanized after 3 weeks for confirmation by dual-energy X-ray absorptiometry (DXA) and ex vivo microCT. A third group was euthanized after one week for gene expression analysis and histomorphometry (see below).

\subsection{DXA}

Bone mineral density (BMD), bone mineral content (BMC) and lean tissue mass were determined in the whole body (minus head) region and separately in the left and right hindlimb region of interest by in vivo DXA using the PIXImus mouse densitometer (Lunar Corp) with an ultrahigh resolution $(0.18 \times$ 0.18 pixels, 1.6 line pairs $/ \mathrm{mm}$ ) and software $\mathrm{v} 1.45$. 


\subsection{MicroCT}

For in vivo microCT, both hindlimbs were scanned consecutively using a SkyScan 1076 (Bruker, Kontich, Belgium) [44] with the following settings: $9 \mu \mathrm{m}$ pixel size, $1.0 \mathrm{~mm}$ Al filter, $50 \mathrm{kV}, 100 \mu \mathrm{A}, 1.0^{\circ}$ rotation step, $180^{\circ}$ angular rotation and $3300 \mathrm{~ms}$ integration time. The field of view included the distal two-thirds of the femur and the proximal two-thirds of the tibia, including the distal tibia-fibula junction. Ex vivo microCT was performed with a SkyScan 1172 microCT (Bruker, Kontich, Belgium) using $5 \mu \mathrm{m}$ pixel size, $0.5 \mathrm{~mm}$ Al filter, $50 \mathrm{kV}, 200 \mu \mathrm{A}, 180^{\circ}$ angular rotation at $0.6^{\circ}$ steps, $590 \mathrm{~ms}$ integration time and averaging of two frames. All images were reconstructed using NRecon and analyzed by CTAn software as described [44]. For trabecular bone, a $1.5 \mathrm{~mm}$ region of interest in the proximal tibial metaphysis was selected, starting at $0.5 \mathrm{~mm}$ from the distal edge of the growth plate. For cortical bone, a $0.25 \mathrm{~mm}$ segment starting $0.5 \mathrm{~mm}$ proximally from the tibia-fibula junction was analyzed. Parameters included trabecular bone volume fraction (BV/TV, \%), trabecular number (Tb.N, 1/mm), trabecular thickness (Tb.Th, $\mathrm{mm}$ ), trabecular separation (Tb.Sp, $\mathrm{mm}$ ), total cross-sectional tissue area (Tt.Ar, $\left.\mathrm{mm}^{2}\right)$, cortical bone area (Ct.Ar, $\left.\mathrm{mm}^{2}\right)$, medullary or marrow area $\left(\mathrm{Ma} . \mathrm{Ar}, \mathrm{mm}^{2}\right)$ cortical thickness (Ct.Th, mm), periosteal perimeter (Ps.Pm, mm), endocortical perimeter (Ec.Pm, mm) and polar moment of inertia $\left(\mathrm{J}, \mathrm{mm}^{4}\right)$. For muscle area (in $\mathrm{mm}^{2}$ ), a single mid-calf slice at $5.0 \mathrm{~mm}$ from the distal edge of the proximal tibial growth plate was analyzed.

\subsection{Bone histomorphometry}

For bone histomorphometry, a group of mice was euthanized 3 weeks after BTx injection and surgery. These mice were injected i.p. with calcein (15 mg/kg; Sigma-Aldrich, St. Louis, MO, USA) 4 and 1 days before euthanasia. Bilateral tibias were fixed in Burkhardt's solution overnight, stored in ethanol for microCT analysis, embedded undecalcified in methylmethacrylate, and sectioned at $4 \mu \mathrm{m}$. Bilateral femurs were fixed overnight in PBS with $2 \%$ paraformaldehyde, stored in PBS, decalcified in $0.5 \mathrm{M}$ ethylenediamine tetraacetic acid (EDTA) in PBS for 2 weeks at $4^{\circ} \mathrm{C}$, followed by dehydratation in graded ethanol concentrations and embedding in paraffin. Paraffin sections $(4 \mu \mathrm{m})$ were cut with a rotary microtome (Menzel-Gläser), dewaxed in xylene and rehydrated before staining. Osteoclasts were visualized with tartrate-resistant acid phosphatase (TRAcP) staining, and osteoclast surface per bone surface (\%) was determined. The trabecular mineralizing surface to bone surface ratio (MS/BS) was calculated as the sum of the double-labeled surfaces (dLS) and the single-labeled surfaces divided by two ([dLS $\left.+0.5^{*} \mathrm{sLS}\right] / \mathrm{BS}$ ). Since double labels were only evident in the ORX and not in 
any of the other groups, the bone formation rate and mineral apposition rate could not be reliably assessed. All images were acquired and analyzed using a Zeiss Axiovert microscope with an Axiovision (v6.1.0) image analysis system using in-house software [38, 45, 46].

\subsection{Quantitative PCR}

For gene expression analyses, mice were euthanized one week after BTx injection and surgery. Hindlimbs were immediately dissected, cleaned of soft tissue and snap-frozen in liquid nitrogen. Total RNA was extracted from crushed tibias using TRIzol reagent (Invitrogen), according to the manufacturer's protocols. After digestion with DNase I (Fermentas, St Leon-Rot, Germany), cDNA was synthesized from $1 \mu \mathrm{g}$ RNA using the RevertAid M-MuLV Reverse Transcriptase kit (Fermentas) and random hexamer primers (Fermentas). The PCR reaction mixtures (10 $\mu$ l) contained $1 \times$ Platinum SYBR Green qPCR SuperMix-UDG (Invitrogen), $0.15 \mu \mathrm{M}$ of each primer, and $50 \mathrm{nM}$ ROX reference dye (Invitrogen). The StepOne Plus Real-Time PCR system (Applied Biosystems, Foster City, CA, USA) was used. The primer sequences are listed in Supplemental Table S1. All primers were designed to hybridize to different exons, and generation of single amplicons was checked in melting curve assays. Gene expression was quantified using the absolute method with normalization to the levels of the housekeeping gene hypoxanthine guanine phosphoribosyl transferase (Hprt) [8].

\subsection{Serum analyses}

Serum was obtained via cardiac puncture and bone turnover markers were assessed after 3 weeks of hormonal manipulation. Mouse serum TRAcP $5 b$ was measured using an enzyme-linked immunosorbent assay from Immunodiagnostic systems (Paris, France) according to manufacturer instructions. Osteocalcin was measured using an in-house radioimmunoassay (RIA) as described previously [47].

\subsection{Statistical analysis}

Differences in continuous variables between sham, $\mathrm{ORX}, \mathrm{ORX}+\mathrm{T}$ and $\mathrm{ORX}+\mathrm{DHT}$ groups were analyzed by one-way ANOVA followed by Bonferroni's multiple comparisons test. For repeated measurements over time or to study the interaction effect between androgen groups and BTx treatment, two-way repeated measures ANOVA with Bonferroni post-test was used. Mean and standard error (SEM) are shown in all graphs unless specified otherwise. Analyses were performed using Graphpad Prism v5.04, and two-tailed $\mathrm{P}<0.05$ was considered significant. 


\section{Results}

\subsection{Effects of androgens on acute disuse osteoporosis}

As expected, BTx injection produced a transient muscle paralysis reflected by both an increase in the digit abduction score [42] (which recovered to baseline levels in approximately 2-3 weeks) and a decrease in the gait function inventory score [25], which recovered incompletely after 2-3 weeks (Fig. 1A, B; $P \leq 0.0001$ for change over time). This effect of BTx was not affected by androgens (nor was there significant interaction) (Fig. 1A, B). In line with previous reports that local BTx treatment produces systemic stress [25], all animals lost body weight, particularly in the first week after injection. This reduction in body weight loss was more pronounced following ORX and less pronounced in the $\mathrm{ORX}+\mathrm{T}$ and $\mathrm{ORX}+\mathrm{DHT}$ groups compared to sham $(\mathrm{P} \leq 0.0001$ for effect of $\mathrm{BTx}$, androgens as well as interaction between treatments) (Fig. 1C). BTx induced atrophy of the quadriceps and calf muscles (gastrocnemius and soleus) $(\mathrm{P} \leq 0.0001)$, which was not prevented by androgens (Fig. 1D, E). Also by $D X A$, lean tissue mass and BMC were decreased by BTx $(P \leq 0.0001)$ with no significant effect of or interaction with androgens (Fig. 1G, I). In contrast, BMD in the hindlimb regions of interest was decreased by both BTx $(P \leq 0.0001)$ and ORX $(P=0.0005)$ (Fig. 1H). 
A

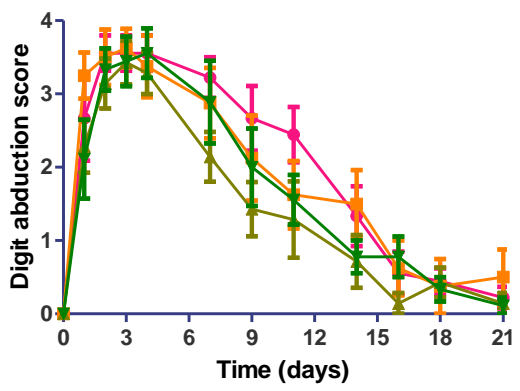

C

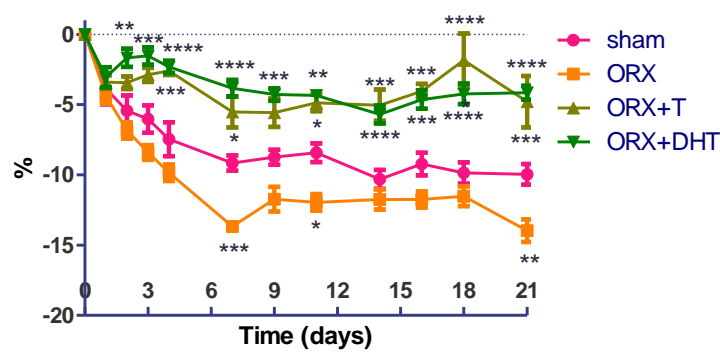

E

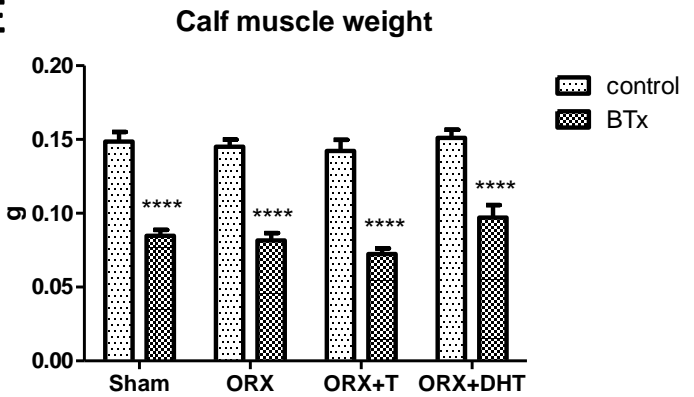

G

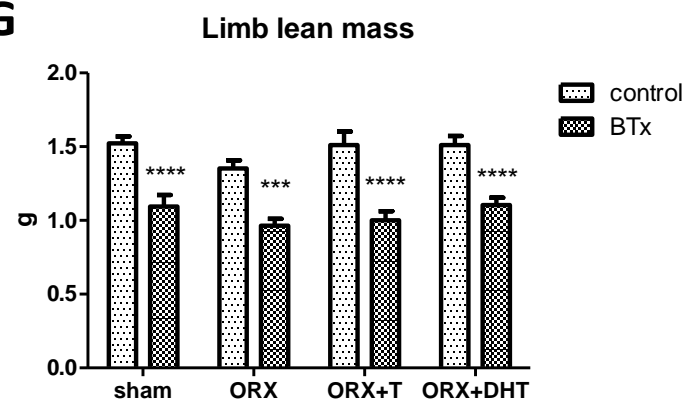

I

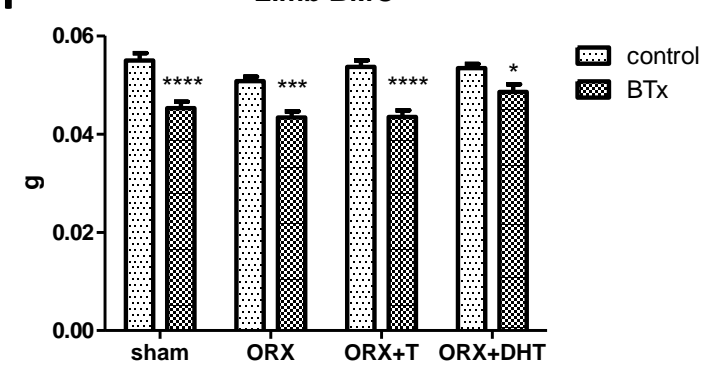

B

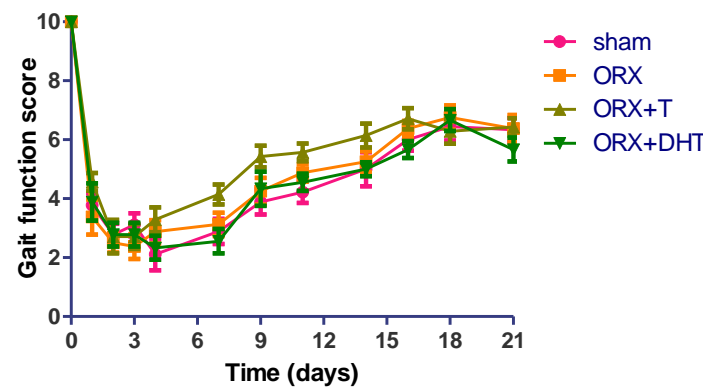

D

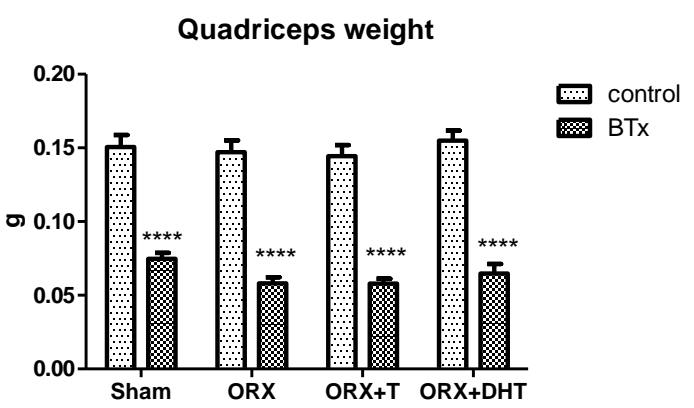

$\mathbf{F}$

Muscle area

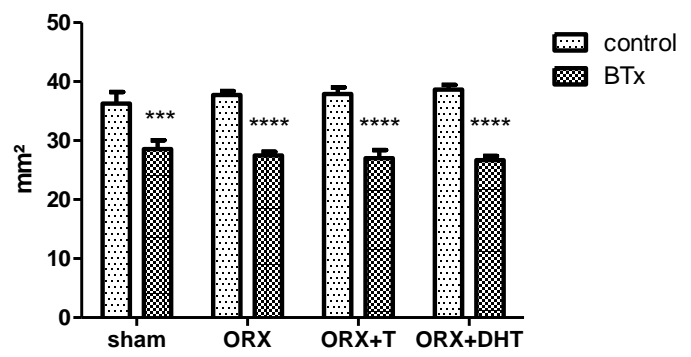

H

Limb BMD

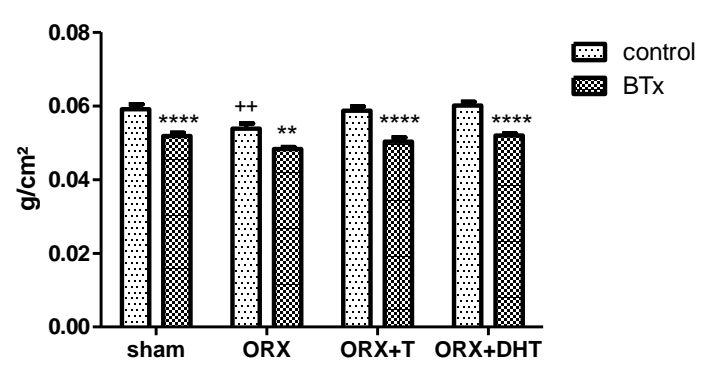

Fig. 1. Acute intervention effects on disability, body and muscle weight.

A) Evolution of the Digit abduction score and B) gait function score following BTx injection. C) Body weight loss (\%) compared to each animal's pre-treatment weight. Bonferroni post-test results are indicated as ${ }^{*}=\mathrm{P}<0.05$, ${ }^{\star \star}$ 
$=P \leq 0.01,{ }^{* * *}=P \leq 0.001,{ }^{* * *}=P \leq 0.0001$. D) Quadriceps muscle weight, E) calf muscle weight, $\mathbf{F}$ ) calf muscle area and G) limb lean mass by DXA after 3 weeks. H) Limb areal BMD and I) BMC by DXA. Asterisks indicate significant difference vs. internal control hindlimb in the same group (=BTx effect). Crosses indicate significant difference vs. same hindlimb in the sham group (=androgen effect). ${ }^{*}=\mathrm{P}<0.05,{ }^{* *},{ }^{++}=\mathrm{P} \leq 0.01,{ }^{* * *}=\leq 0.001$, ${ }^{* * \star *}=\mathrm{P} \leq 0.0001 . \mathrm{N}=7-9$ animals per group in all panels.

The dose of androgens was judged to be slightly supraphysiological based on the weights of the androgen-sensitive seminal vesicle and LA/BC muscles. In serum, both the bone resorption marker TRAcP $5 \mathrm{~b}$ and the bone formation marker osteocalcin were increased by ORX and restored by $\mathrm{T}$ and DHT at the end of the 3 week intervention (Table 1).

Table 1. Acute intervention effects on androgen status and bone turnover.

\begin{tabular}{|c|c|c|c|c|c|}
\hline & Sham & ORX & ORX+T & $\mathrm{ORX}+\mathrm{DHT}$ & $P$ value \\
\hline Seminal vesicle & $0.2974 \pm$ & $0.0496 \pm$ & $0.4157 \pm$ & $0.4612 \pm$ & \multirow{2}{*}{$\leq 0.0001$} \\
\hline weight $(\mathrm{g})$ & 0.0120 & $0.0080^{\star * *}$ & $0.0130^{\star * *}$ & $0.0200^{\star * *}$ & \\
\hline \multirow{2}{*}{ LA/BC weight $(\mathrm{g})$} & $0.0841 \pm$ & $0.0420 \pm$ & $0.0966 \pm$ & $0.0969 \pm$ & \multirow{2}{*}{$\leq 0.0001$} \\
\hline & 0.0025 & $0.0014^{\star \star *}$ & $0.0044^{\star \star}$ & $0.0057^{\star *}$ & \\
\hline \multirow{2}{*}{$\operatorname{BMD}\left(\mathrm{g} / \mathrm{cm}^{2}\right)$} & $0.0475 \pm$ & $0.0454 \pm$ & $0.0468 \pm$ & $0.0487 \pm$ & \multirow{2}{*}{0.001} \\
\hline & 0.0005 & $0.0006^{*}$ & 0.0006 & 0.0003 & \\
\hline TRAcP 5b (U/L) & $5.27 \pm 0.56$ & $7.01 \pm 0.36$ ** & $3.47 \pm 0.42$ * & $3.85 \pm 0.24$ * & $<0.0001$ \\
\hline $\begin{array}{l}\text { Osteocalcin } \\
\text { (ng/mL) }\end{array}$ & $38.0 \pm 6.5$ & $66.1 \pm 6.0^{\star *}$ & $25.2 \pm 3.1$ & $21.2 \pm 2.4$ & $\leq 0.0001$ \\
\hline
\end{tabular}

Results are shown as mean \pm SEM. $\mathrm{N}=7-9$ for all outcomes. ${ }^{*}=\mathrm{P}<0.05,{ }^{\star \star}=\mathrm{P}<0.01,{ }^{\star \star \star}=\mathrm{P}<0.001$ in Bonferroni post-test compared to sham.

Trabecular bone volume at the end of the 3 week acute phase showed a significant effect of BTx, androgens as well as their interaction (all $\mathrm{P} \leq 0.0001$ ) (Fig. $2 \mathrm{~A}$ ). In the control limb, BV/TV loss was induced by ORX, prevented by DHT and even slightly above sham levels in the ORX+T group. BTX reduced $B V / T V$ ( $P \leq 0.0001$ in all groups), however the difference attributable to BTx (in \% compared to each animal's internal control hindlimb) was greater in ORX and lower in the ORX+DHT group 
compared to sham (Fig. 2B). Note that the difference in $\mathrm{ORX}+\mathrm{T}$ was not significant in this analysis because of the higher BV/TV in the control leg. These differences were mainly due to changes in trabecular number (Fig. 2C), which also showed effects of androgens and BTx (both $P \leq 0.0001$ ) as well as interaction $(P=0.007)$. Again, the $B T x$-related difference was significantly lower in $O R X+T$ and $\mathrm{ORX}+\mathrm{DHT}$ than in ORX (Fig. 2D). Trabecular thickness (Tb.Th) was also affected by BTX (P $\leq$ $0.0001)$, however less so by androgens $(P=0.01)$. Still, the decrease in $\mathrm{Tb}$.Th in the control hindlimb following ORX was prevented by T (but not DHT) (Fig. 2E). Trabecular separation on the other hand was mainly affected by $\mathrm{ORX}(\mathrm{P} \leq 0.0001)$ and less so by $B T x(P=0.009)$, with no significant interaction (Fig. 2F). 
A

Trabecular bone volume

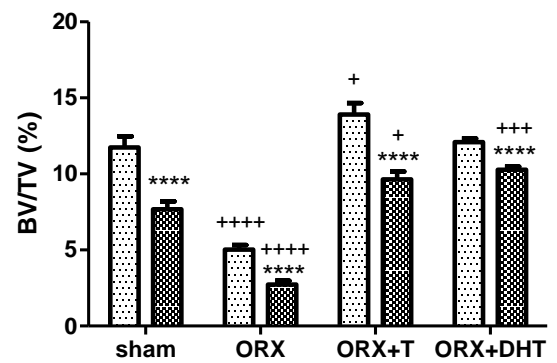

C

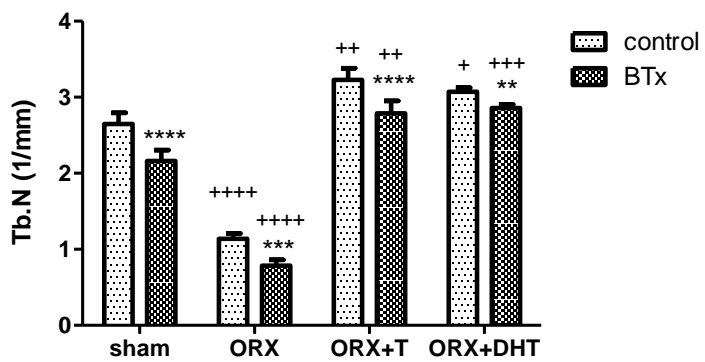

E
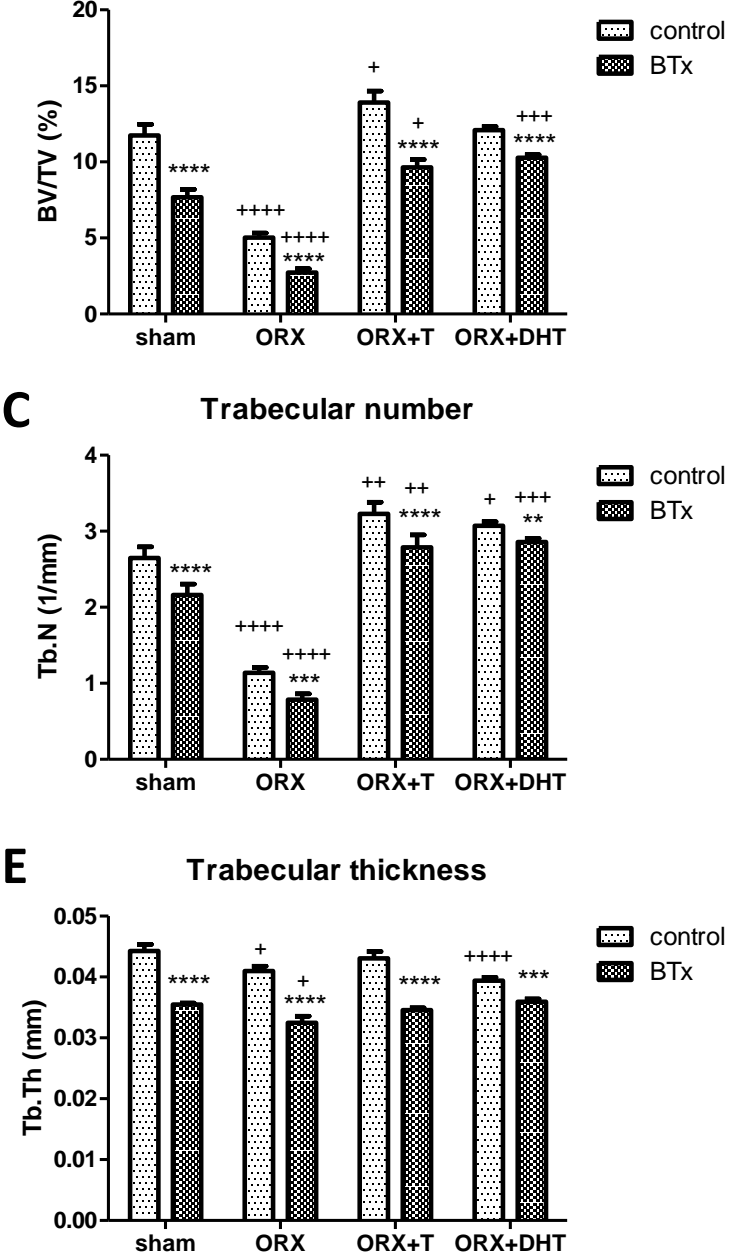

B BT $x$-related relative BV/TV difference

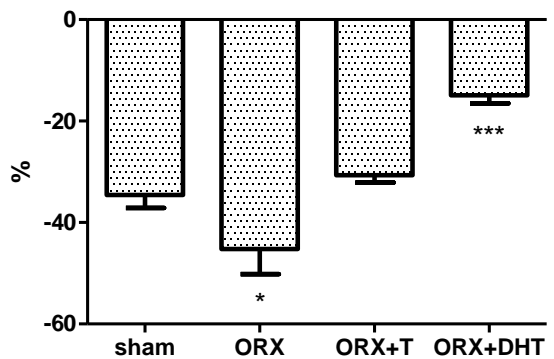

D BTx-related relative Tb.N difference

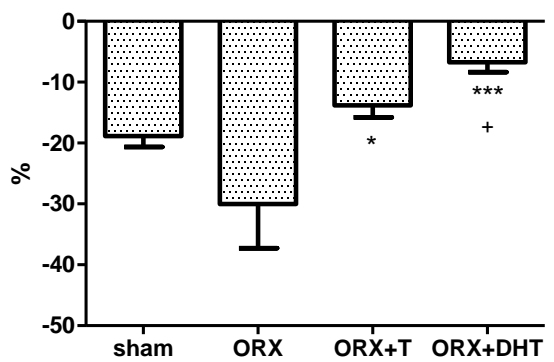

F

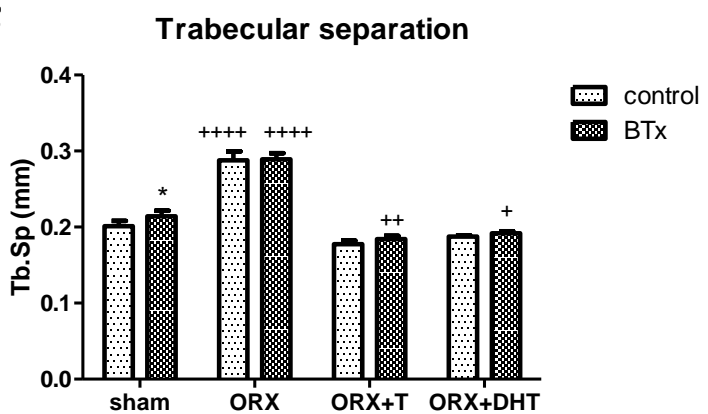

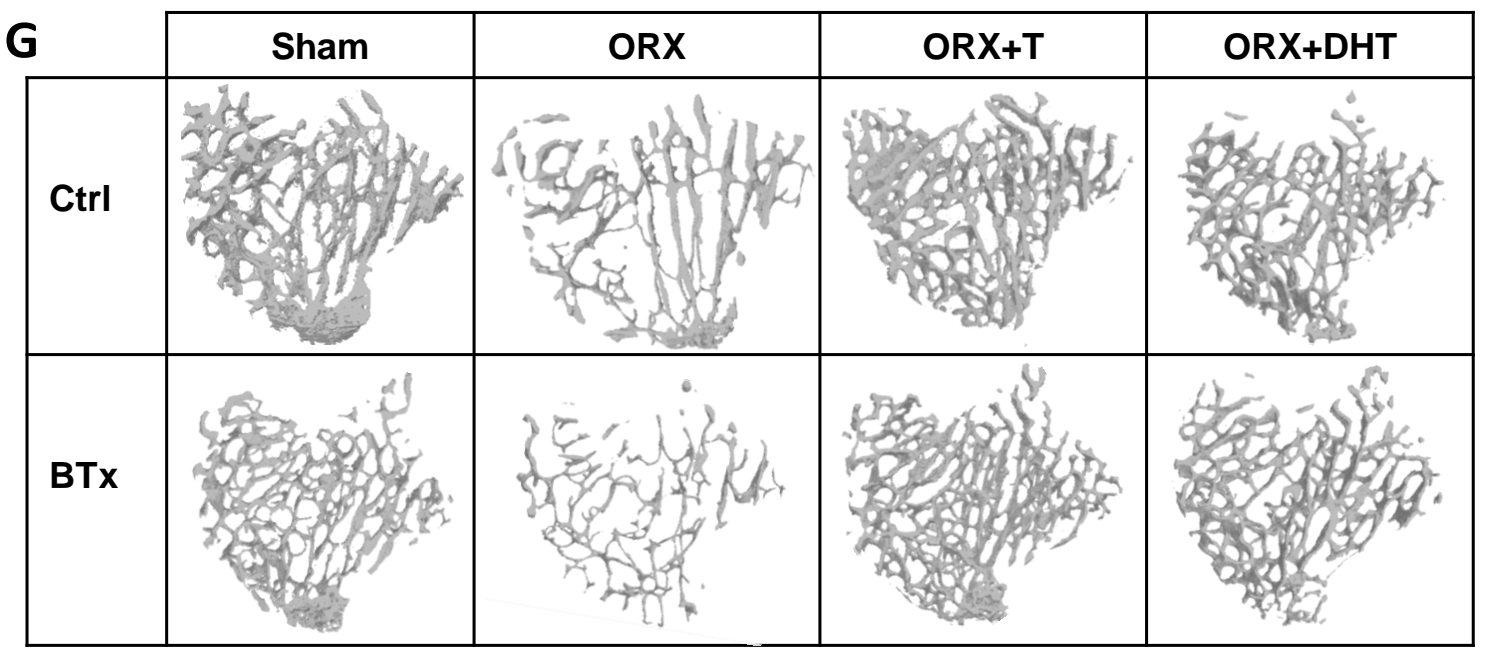

Fig. 2. Effects of androgens on acute disuse osteoporosis.

A) Trabecular bone volume in the proximal tibial metaphysis. B) BTx-related relative BV/TV difference (i.e. \% difference compared to the internal control hindlimb in each animal). ${ }^{*}=\mathrm{P}<0.05,{ }^{*}=\mathrm{P}<0.001$ vs. sham. C) Trabecular number, D) BTx-related relative Tb.N difference. ${ }^{*}=\mathrm{P}<0.05,{ }^{* * *}=\mathrm{P}<0.001$ vs. sham, ${ }^{+}=\mathrm{P}<0.05$ vs. ORX. E) Trabecular thickness, F) Trabecular separation. In graphs A, C, E and F, asterisks indicate 
significant difference vs. internal control hindlimb in the same group (=BTx effect), whereas crosses indicate significant difference vs. same hindlimb in the sham group (=androgen effect). N=7-9 animals per group in all panels. G) Representative 3D models of trabecular region of interest (proximal $0.5 \mathrm{~mm}$ ).

Regarding cortical bone parameters, BTx reduced Ct.Th and Ct.Ar and increased Ma.Ar and Ec.Pm (Table 2). ORX also reduced Ct.Th and increased Ma.Ar. 
Table 2. Cortical bone microcT parameters.

\begin{tabular}{|c|c|c|c|c|c|c|c|c|c|c|c|}
\hline & Sham & Sham & ORX & ORX & $\mathrm{T}$ & $\mathrm{T}$ & DHT & DHT & $P$ & $\mathrm{P}$ & Inter- \\
\hline & ctrl & BTx & ctrl & BTx & ctrl & BTx & ctrl & BTx & BTx & ORX & action \\
\hline $\operatorname{Tt} . \operatorname{Ar}\left(\mathrm{mm}^{2}\right)$ & $1.228 \pm 0.030$ & $1.215 \pm 0.032$ & $1.339 \pm 0.081$ & $1.278 \pm 0.040$ & $1.181 \pm 0.093$ & $1.144 \pm 0.055$ & $1.245 \pm 0.022$ & $1.243 \pm 0.026$ & N.S. & N.S. & N.S. \\
\hline Ct.Ar $\left(\mathrm{mm}^{2}\right)$ & $0.778 \pm 0.021$ & $0.716 \pm 0.016^{*}$ & $0.796 \pm 0.055$ & $0.702 \pm 0.031^{\star *}$ & $0.780 \pm 0.058$ & $0.688 \pm 0.027^{\star *}$ & $0.745 \pm 0.011$ & $0.694 \pm 0.017^{*}$ & $\leq 0.0001$ & N.S. & N.S. \\
\hline $\operatorname{Ma} \cdot \operatorname{Ar}\left(\mathrm{mm}^{2}\right)$ & $0.451 \pm 0.019$ & $0.498 \pm 0.021$ & $0.543 \pm 0.028$ & $0.576 \pm 0.023$ & $0.401 \pm 0.036$ & $0.456 \pm 0.036$ & $0.500 \pm 0.019$ & $0.549 \pm 0.020$ & 0.0002 & 0.003 & N.S. \\
\hline Ct.Th (mm) & $0.131 \pm 0.002$ & $0.122 \pm 0.002^{\star * \star}$ & $0.122 \pm 0.002^{+}$ & $0.115 \pm 0.003^{*}$ & $0.133 \pm 0.002$ & $0.122 \pm 0.003^{\star \star *}$ & $0.126 \pm 0.002$ & $0.118 \pm 0.002^{* *}$ & $\leq 0.0001$ & 0.007 & N.S. \\
\hline Ps.Pm (mm) & $4.284 \pm 0.053$ & $4.265 \pm 0.059$ & $4.534 \pm 0.163$ & $4.392 \pm 0.082$ & $4.219 \pm 0.170$ & $4.168 \pm 0.112$ & $4.331 \pm 0.044$ & $4.292 \pm 0.048$ & N.S. & N.S. & N.S. \\
\hline Ec.Pm (mm) & $2.864 \pm 0.068$ & $3.044 \pm 0.078^{\star *}$ & $3.065 \pm 0.110$ & $3.210 \pm 0.091$ & $2.748 \pm 0.156$ & $2.856 \pm 0.124$ & $2.996 \pm 0.072$ & $3.136 \pm 0.061$ & $\leq 0.0001$ & N.S. & N.S. \\
\hline$J\left(\mathrm{~mm}^{4}\right)$ & $0.214 \pm 0.010$ & $0.202 \pm 0.009$ & $0.247 \pm 0.028$ & $0.212 \pm 0.013^{*}$ & $0.210 \pm 0.036$ & $0.184 \pm 0.018$ & $0.215 \pm 0.007$ & $0.204 \pm 0.009$ & 0.002 & N.S. & N.S. \\
\hline
\end{tabular}

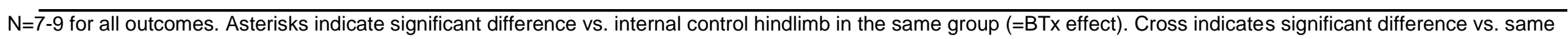
hindlimb in the sham group (=ORX effect on Ct.Th). ${ }^{*}{ }^{+}=\mathrm{P}<0.05,{ }^{* *}=\mathrm{P}<0.01,{ }^{* *}=\mathrm{P}<0.001$ in Bonferroni post-test. N.S. $=$ not significant. 
TRAcP staining on trabecular bone at the end of the 3 week period revealed that average Oc.S/BS was significantly increased by $\mathrm{ORX}(\mathrm{P}=0.0002)$ as well as by $\mathrm{BTx}(\mathrm{P}=0.02)$, with the highest Oc.S/BS in the BTx hindlimb of the ORX group (Fig. 3A). The mineralizing surface (MS/BS) was increased by ORX and restored by T and DHT, with no significant effect of BTx (Fig. 3B). Representative microphotographs of the trabecular TRAcP staining are shown in Fig. 3C. To study the early changes in gene expression following BTx and androgen treatment, a separate group of mice was euthanized after one week. Results of qPCR analysis showed that both BTx ( $P=0.006)$ and ORX ( $P=0.02)$ increased Trap expression (Fig. 3E). A similar pattern was observed for Ctsk expression (BTx $P=0.0005)$ although the effect of androgens was not significant (Fig. 3F). There was no significant effect of either treatment on Tnfrsf11a (Rank), Tnfsf11 (Rank) or Tnfrsf11b (osteoprotegerin, Opg) expression, but the Rankl/Opg mRNA ratio was increased by BTx ( $\mathrm{P}=0.001)$ (data not shown). There were no significant effects of either treatment after one week on Sp7, Tgfb1, Dmp1 or Sost expression (data not shown). 
A

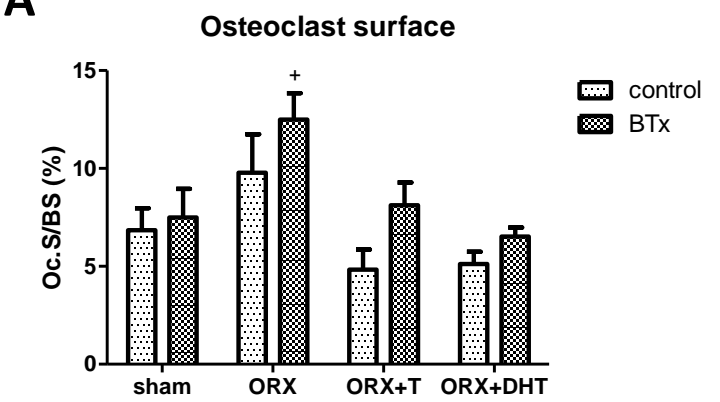

B
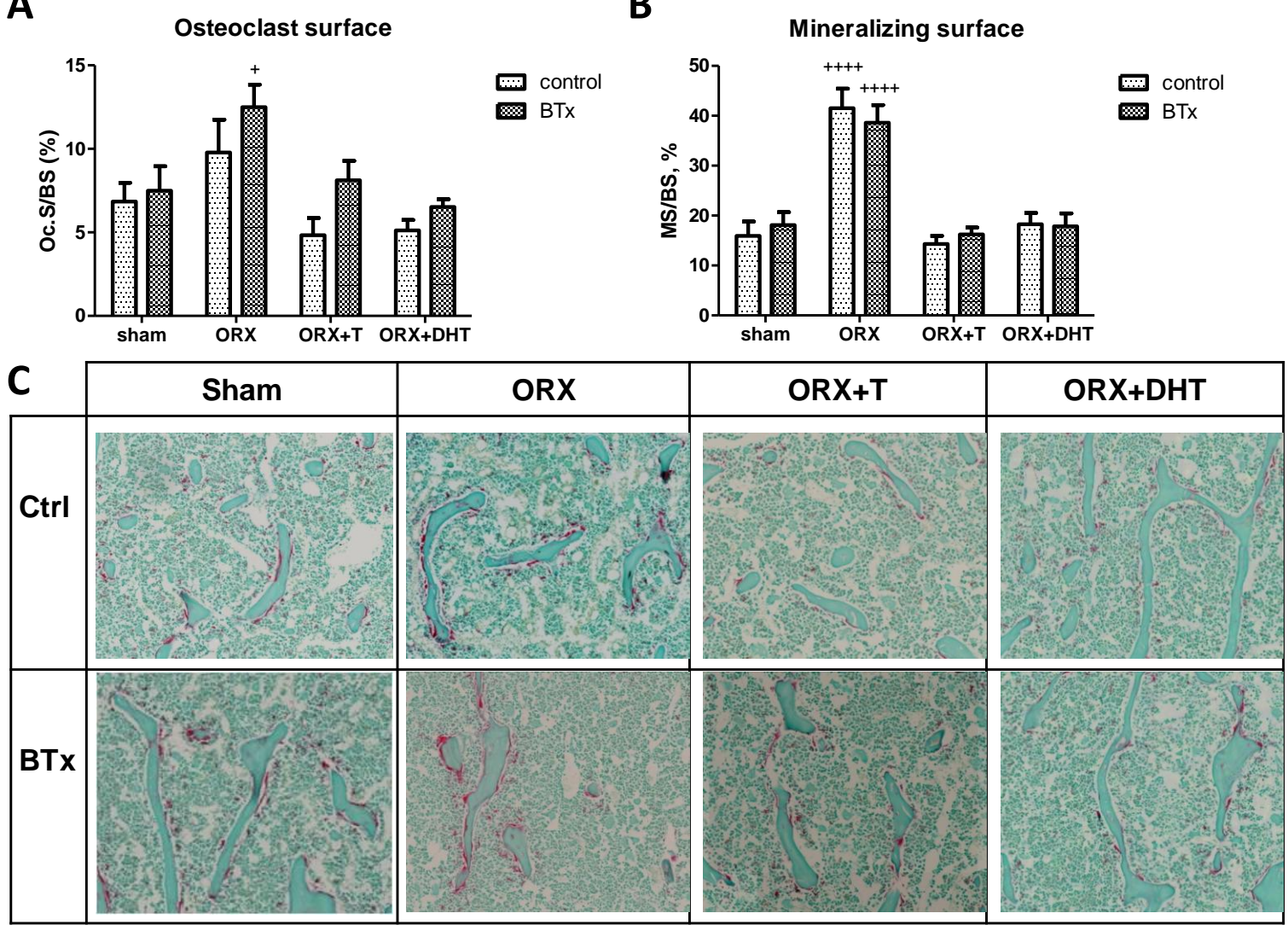

D

Trap expression

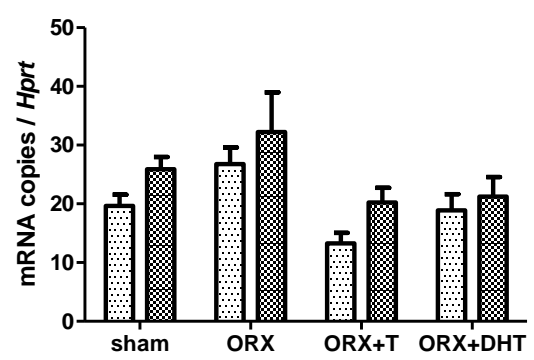

E

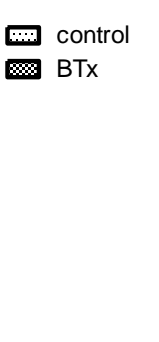

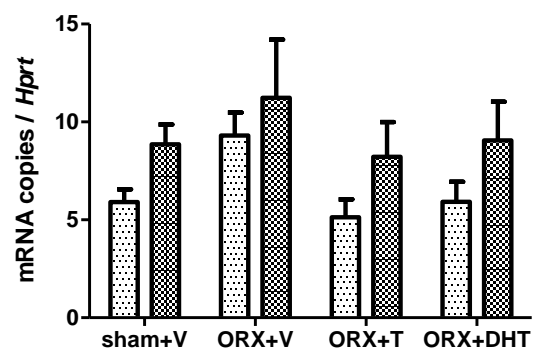

Fig. 3. Effects of androgens on osteoclast surface, mineralizing surface and gene expression in early disuse osteoporosis.

A) Osteoclast surface by TRAcP staining on trabecular surfaces in the distal femoral metaphysis. B) Mineralizing surface by calcein labeling in the proximal tibial metaphysis. $\mathrm{N}=7-9$ per condition in panels $\mathrm{A}-\mathrm{B} .{ }^{+}=\mathrm{P}<0.05,{ }^{+++}$ $=\mathrm{P} \leq 0.0001$ effect of androgens in Bonferroni post-test. C) Representative microphotographs of trabecular TRACP staining in different conditions. D) Trap and E) Ctsk gene expression by qPCR. N=10 per condition in panels D-E. 


\subsection{Effects of androgens on recovery from acute disuse osteoporosis}

The long-term effects of androgens during the recovery phase were examined in a separate group of mice which also received BTx at 16 weeks of age. As judged by androgen-sensitive organ weights, ORX remained effective and the dose of T and DHT was again slightly supraphysiological (data not shown). The in vivo microCT results for trabecular bone are shown in Fig. 4A. After 7 weeks, BV/TV in both hindlimbs in the ORX groups was profoundly diminished such that meaningful quantification was no longer possible. At the end of this long-term study (week 19, age 26 weeks), there was a significant effect of both BTx ( $\mathrm{P} \leq 0.0001)$ and androgens $(\mathrm{P}=0.007)$ on BV/TV (Fig. 4B). Specifically, a significant difference remained at the end of the study period between the BTx and control hindlimbs in the sham group $(\mathrm{P}<0.01$ by Bonferroni post-test). In the $\mathrm{ORX}+\mathrm{DHT}$ group however, BV/TV in the BTx hindlimb was restored to sham-control levels, and the difference between the BTx and control limb was no longer significant in the $\mathrm{ORX}+\mathrm{DHT}$ group. In the $\mathrm{ORX}+\mathrm{T}$ group, BV/TV was restored to pre-treatment levels and increased above sham-control levels in both the BTx $(P<0.05)$ and control $(\mathrm{P}<0.01)$ hindlimbs.

A Trabecular bone volume (in vivo microCT)

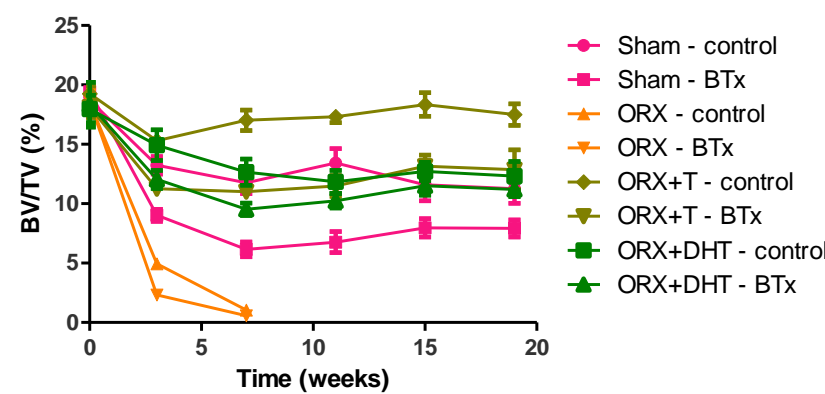

B

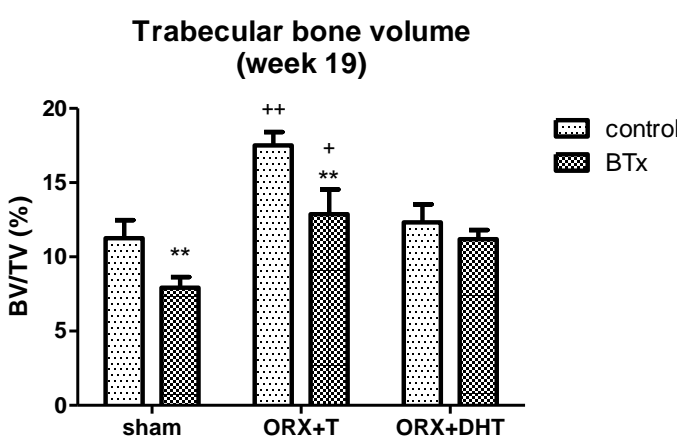

Fig. 4. Effects of androgens on recovery from acute disuse osteoporosis.

A) Trabecular bone volume in the proximal tibial metaphysis. B) Results at the end of the 19 week study period. $\mathrm{N}=9$ for sham and $\mathrm{ORX}$ groups, and $\mathrm{N}=5$ for $\mathrm{ORX}+\mathrm{T}$ and $\mathrm{ORX}+\mathrm{DHT}$ groups. Asterisks indicate significant difference vs. internal control hindlimb in the same group (=BTx effect). Crosses indicate significant difference vs. same hindlimb in the sham group (=androgen effect). ${ }^{+}=\mathrm{P}<0.05,{ }^{* *},{ }^{++}=\mathrm{P}<0.01$ in Bonferroni post-test. 


\subsection{Effects of conditional AR deletion using Dmp1-Cre and MyoD-Cre}

To investigate the possible target cells of the effects of androgens on disuse osteoporosis, we performed in vivo microCT in mice with conditional AR deletion in osteoblasts and osteocytes using Dmp1-Cre (ocyARKO mice) [8], and in the satellite cell lineage using MyoD-Cre (satARKO mice) [40]. We hypothesized that conditional ARKO might reproduce the effect of ORX and result in greater BTXrelated relative BV/TV difference compared to that of control mice.

The results showed no difference in either the control or BTx leg between ocyARKO and controls at 0 , 3 or 7 weeks. At the 11 week time point (age 27 weeks), BV/TV loss became apparent in both the control and BTx limb of ocyARKO compared to controls, consistent with our previously reported phenotype at 32 weeks of age [8] (Fig. 5A). However the BTx-related difference (data not shown) was not increased in ocyARKO mice.

In satARKO mice, there was no significant BV/TV difference after 0 or 3 weeks (data not shown). At the 7 week time point however, there was a significant effect of both BTx $(P=0.0025)$ and satARKO $(P$ $=0.016$ ) with no significant interaction (Fig. 5B). Specifically, satARKO mice had lower BV/TV in both hindlimbs, but the BTx-related difference (data not shown) was not significantly different compared to control mice.

A

OcyARKO

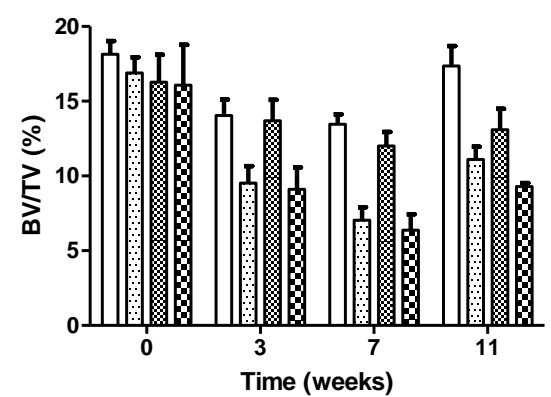

B

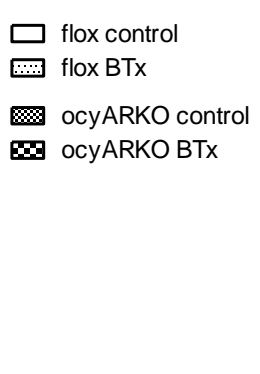

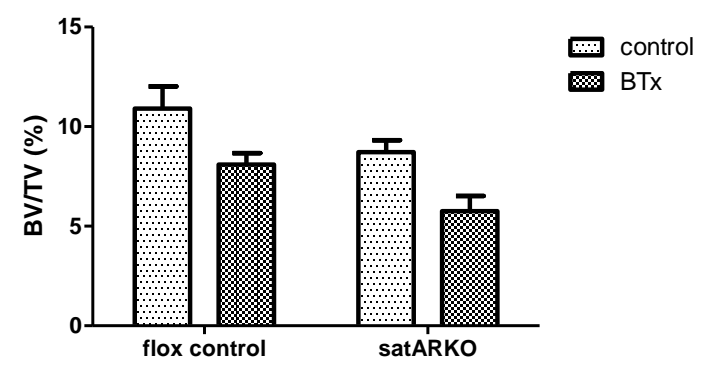

Fig. 5. Effects of conditional AR deletion using Dmp1-Cre (ocyARKO) or MyoD-Cre (satARKO) on acute disuse osteoporosis.

A) Trabecular bone volume in the proximal tibial metaphysis by in vivo microCT in BTx and control hindlimbs of $\operatorname{ocyARKO}(\mathrm{N}=7)$ and flox control mice $(\mathrm{N}=10)$, and $\mathrm{B})$ satARKO $(\mathrm{N}=8)$ and control mice $(\mathrm{N}=13)$ after 7 weeks. 


\section{Discussion}

Androgens are an interesting candidate treatment for simultaneous bone loss and muscle atrophy as shown by previous preclinical studies on disuse osteosarcopenia [14, 16, 20, 33, 35, 36]. However, it is unclear whether the preventive actions of androgens on disuse osteoporosis are mediated via a direct effect on bone or merely result from indirect androgen effects on muscle.

Our main findings are that both $\mathrm{T}$ and $\mathrm{DHT}$ mitigate BTx-induced trabecular bone resorption, in line with the known effects of AR on trabecular bone maintenance $[3,6-10]$. This confirms findings in ARKO mice which have been reported to display greater hindlimb unloading-induced bone loss [48]. Orchidectomy increased not only bone resorption but also bone formation, as assessed by dynamic histomorphometry (Fig. 3B) and serum osteocalcin and TRAcP 5b concentrations (Table 1). This is expected since bone formation and resorption are coupled, and androgens are known to inhibit trabecular bone resorption by restraining bone turnover via an effect on osteoblasts $[49,50]$. Thus, although androgens did not preserve trabecular bone via an effect on bone formation in our study, the effect of T may be different during growth since it was recently reported that disuse reduced trabecular bone formation which was restored by T at supraphysiological doses in young rats [20]. In both shortterm and long-term experiments however, we found that $\mathrm{T}$ was more effective than $\mathrm{DHT}$ in restoring trabecular bone volume. T also prevented BTx-induced endosteal expansion whereas DHT did not, suggesting that aromatization and estrogens are important for these effects of $\mathrm{T}$. This is in line with the known effects of ERa on the trabecular and endosteal compartment in male mice [2, 3, 9, 51]. Thus, although pure androgens may exert some antiresorptive effects on the trabecular compartment, highdose T therapy may be more effective given the importance of aromatization for male skeletal health.

Secondly, our data also clearly indicate that the prevention of disuse osteopenia by androgens did not require androgen effects on muscle. This was supported by the finding that androgens had no noticeable effects on BTx-induced paralysis or consequent limb lean mass, muscle weight or muscle area loss, although we cannot exclude a possible effect on other muscle properties or quality [40]. Other studies have likewise reported no effect of androgens on skeletal muscle loss in rodent acute disuse models, although this may depend on the timing of administration [14, 52, 53]. In mice, developmental AR deletion or ORX in young mice has significant but weak effects on appendicular muscle mass [40]. In adult mice however, we show that ORX without or with T or DHT replacement has no significant effect on appendicular muscle mass (and also not on grip strength, unpublished 
data). Although androgens have an effect on both muscle mass and strength in humans, it is well known that anabolic effects are best achieved by combining androgens with resistance training [12, 54]. In contrast, androgens at supraphysiological doses were able to prevent trabecular bone loss in our BTx study. Bone loss in this model is believed to result primarily from absence of muscle contractions [29]. Hence, our findings do not exclude the possibility that androgens might prevent acute disuse muscle atrophy in humans, but at least they support the conclusion that androgen effects on trabecular disuse osteopenia in mice are independent of the muscle anabolic actions of androgens.

Furthermore, conditional deletion of AR in the satellite cell lineage $[40,41]$ was associated with accelerated age-related trabecular bone loss in both hindlimbs, similar to what we observed previously in ocyARKO mice [8]. This observation is novel and suggests indeed that developmental AR deletion in the satellite cell-lineage has not only direct effects on muscle but might also have secondary effects on bone, although further investigations are required to confirm these preliminary results [5]. Importantly however, the effect of BTx on trabecular bone was not increased in satARKO like in ORX, suggesting again that the effects of androgens on muscle are not a prerequisite for their prevention of disuse osteoporosis.

Studies have shown that ERaKO mice (which have decreased bone turnover) have a diminished osteogenic response to mechanical loading $[2,55,56]$ while ovariectomized, ARKO and ORX mice have increased bone turnover and display increased skeletal mechanoresponsivity $[37,38]$. Thus, in combination with previous studies [37, 38, 48], it appears that androgens, via their anti-remodeling effect blunt both the detrimental skeletal effects of unloading as well as the bone-anabolic effects of mechanical stimulation. This is similar to what has been described for bisphosphonates (although androgens inhibit bone turnover by acting on osteoblasts rather than osteoclasts). The increased bone turnover and remodeling space following orchidectomy may determine the greater subsequent response (both positive and negative) to loading and unloading.

Osteocytes are believed to play an important role in mechanosensitivity and skeletal adaptation to mechanical stimuli or disuse $[14,57]$. However, neither osteocyte-specific ERaKO or ARKO male mice have an altered response to mechanical loading, suggesting that osteocytes are not the target cells of the effects of ERa and androgens $[8,58,59]$. Thus, it is not unexpected that ocyARKO also did not have greater trabecular bone loss following acute disuse like ORX mice did. The antiresorptive effects 
of androgens are unlikely to be explained by $A R$ in osteoclasts either $[9,10]$. This leaves open several possible alternative target cells or mechanisms, the most likely of which is in our opinion a direct effect of androgens on osteoprogenitor cells or early osteoblasts [9]. Another interesting possibility in this regard was the systemic effect of androgens on body weight, since bone is well known to adapt to increasing bodily loads. Further studies using different conditional knock-out models e.g. osteoprogenitor cell-targeting Cre drivers [49], or different unloading techniques which allow correction for body weight [60] are required to investigate these possibilities. Another limitation of this study is that our Cre/LoxP knock-out models may not have completely abrogated AR expression and that compensatory effects may occur through other AR expressing cells e.g. muscle-resident fibroblasts [8, 41]. Finally, we did not have non-irradiated controls in our long-term in vivo microCT studies, although our protocol produced a radiation dose of only 434 mGy which was previously validated to have no effect on trabecular microarchitecture per se after 3 sessions with a two week interval [45].

We conclude that androgens like DHT can prevent trabecular disuse osteopenia in adult male mice via an antiresorptive mechanism, while T has additional effects on BTx-induced trabecular and endosteal bone loss. AR in the satellite cell lineage or in osteocytes also regulates trabecular bone volume, but these mechanisms are dispensable for androgens to mitigate disuse osteoporosis. T therapy is an appealing candidate therapy which should be evaluated further in randomized clinical trials in hypogonadal men with disuse osteoporosis and/or sarcopenia.

\section{Acknowledgements}

We thank E. Van Herck, L. Deboel, K. Moermans, R. Van Looveren and R. Bollen for excellent technical assistance, and L. Antonio and B. Decallonne for helpful discussions related to this work. This work was supported by the Research Foundation Flanders (FWO) [grant G085811N] and the KU Leuven Research Council [grant GOA/15/017]. MRL and VD have been supported by PhD Fellowships and FJ by a post-doc grant from the Research Foundation Flanders (FWO).

\section{References}

[1] Carson JA, Manolagas SC. Effects of sex steroids on bones and muscles: Similarities, parallels, and putative interactions in health and disease. Bone 2015; 80: 67-78.

[2] Vanderschueren D, Laurent MR, Claessens F, Gielen E, Lagerquist MK, Vandenput L, Borjesson AE, Ohlsson C. Sex steroid actions in male bone. Endocr Rev 2014; 35: 906-60. 
[3] Manolagas SC, O'Brien CA, Almeida M. The role of estrogen and androgen receptors in bone health and disease. Nat Rev Endocrinol 2013; 9: 699-712.

[4] Davey RA, MacLean HE, McManus JF, Findlay DM, Zajac JD. Genetically modified animal models as tools for studying bone and mineral metabolism. J Bone Miner Res 2004; 19: 882-92.

[5] Manolagas SC, Kronenberg HM. Reproducibility of results in preclinical studies: a perspective from the bone field. J Bone Miner Res 2014; 29: 2131-40.

[6] Notini AJ, McManus JF, Moore A, Bouxsein M, Jimenez M, Chiu WS, Glatt V, Kream BE, Handelsman DJ, Morris HA, Zajac JD, Davey RA. Osteoblast deletion of exon 3 of the androgen receptor gene results in trabecular bone loss in adult male mice. J Bone Miner Res 2007; 22: 347-56. [7] Chiang C, Chiu M, Moore AJ, Anderson PH, Ghasem-Zadeh A, McManus JF, Ma C, Seeman E, Clemens TL, Morris HA, Zajac JD, Davey RA. Mineralization and bone resorption are regulated by the androgen receptor in male mice. J Bone Miner Res 2009; 24: 621-31.

[8] Sinnesael M, Claessens F, Laurent M, Dubois V, Boonen S, Deboel L, Vanderschueren D. Androgen receptor (AR) in osteocytes is important for the maintenance of male skeletal integrity: evidence from targeted AR disruption in mouse osteocytes. J Bone Miner Res 2013; 27: 2535-43. [9] Ucer S, lyer S, Bartell SM, Martin-Millan M, Han L, Kim HN, Weinstein RS, Jilka RL, O'Brien CA, Almeida M, Manolagas SC. The Effects of Androgens on Murine Cortical Bone Do Not Require AR or ERalpha Signaling in Osteoblasts and Osteoclasts. J Bone Miner Res 2015; 30: 1138-49.

[10] Sinnesael M, Jardi F, Deboel L, Laurent MR, Dubois V, Zajac JD, Davey RA, Carmeliet G, Claessens F, Vanderschueren D. The androgen receptor has no direct antiresorptive actions in mouse osteoclasts. Mol Cell Endocrinol 2015; 411: 198-206.

[11] Venken K, De Gendt K, Boonen S, Ophoff J, Bouillon R, Swinnen JV, Verhoeven G, Vanderschueren D. Relative impact of androgen and estrogen receptor activation in the effects of androgens on trabecular and cortical bone in growing male mice: a study in the androgen receptor knockout mouse model. J Bone Miner Res 2006; 21: 576-85.

[12] Bhasin S, Storer TW, Berman N, Callegari C, Clevenger B, Phillips J, Bunnell TJ, Tricker R, Shirazi A, Casaburi R. The effects of supraphysiologic doses of testosterone on muscle size and strength in normal men. N Engl J Med 1996; 335: 1-7.

[13] Borst SE, Yarrow JF, Conover CF, Nseyo U, Meuleman JR, Lipinska JA, Braith RW, Beck DT, Martin JS, Morrow M, Roessner S, Beggs LA, McCoy SC, Cannady DF, 2nd, Shuster JJ. 
Musculoskeletal and prostate effects of combined testosterone and finasteride administration in older hypogonadal men: a randomized, controlled trial. Am J Physiol Endocrinol Metab 2014; 306: E433-42.

[14] Laurent MR, Dubois V, Claessens F, Verschueren SM, Vanderschueren D, Gielen E, Jardi F. Muscle-bone interactions: From experimental models to the clinic? A critical update. Mol Cell Endocrinol 2016.

[15] Girgis CM, Mokbel N, Digirolamo DJ. Therapies for musculoskeletal disease: can we treat two birds with one stone? Curr Osteoporos Rep 2014; 12: 142-53.

[16] Wimalawansa SM, Chapa MT, Wei JN, Westlund KN, Quast MJ, Wimalawansa SJ. Reversal of weightlessness-induced musculoskeletal losses with androgens: quantification by MRI. J Appl Physiol (1985) 1999; 86: 1841-6.

[17] Boonen S, Vanderschueren D, Cheng XG, Verbeke G, Dequeker J, Geusens P, Broos P, Bouillon R. Age-related (type II) femoral neck osteoporosis in men: biochemical evidence for both hypovitaminosis D- and androgen deficiency-induced bone resorption. J Bone Miner Res 1997; 12: 2119-26.

[18] Strollo F, Boitani C, Basciani S, Pecorelli L, Palumbo D, Borgia L, Masini MA, More M, Strollo G, Spera G, Uva BM, Riondino G. The pituitary-testicular axis in microgravity: analogies with the aging male syndrome. J Endocrinol Invest 2005; 28: 78-83.

[19] Qin W, Bauman WA, Cardozo C. Bone and muscle loss after spinal cord injury: organ interactions. Ann N Y Acad Sci 2010; 1211: 66-84.

[20] Yarrow JF, Conover CF, Beggs LA, Beck DT, Otzel DM, Balaez A, Combs SM, Miller JR, Ye F, Aguirre JI, Neuville KG, Williams AA, Conrad BP, Gregory CM, Wronski TJ, Bose PK, Borst SE. Testosterone dose dependently prevents bone and muscle loss in rodents after spinal cord injury. J Neurotrauma 2014; 31: 834-45.

[21] De Naeyer H, Lamon S, Russell AP, Everaert I, De Spaey A, Jamart C, Vanheel B, Taes Y, Derave W. Effects of tail suspension on serum testosterone and molecular targets regulating muscle mass. Muscle Nerve 2015; 52: 278-88.

[22] Basaria S, Coviello AD, Travison TG, Storer TW, Farwell WR, Jette AM, Eder R, Tennstedt S, Ulloor J, Zhang A, Choong K, Lakshman KM, Mazer NA, Miciek R, Krasnoff J, Elmi A, Knapp PE, Brooks B, Appleman E, Aggarwal S, Bhasin G, Hede-Brierley L, Bhatia A, Collins L, LeBrasseur N, 
Fiore LD, Bhasin S. Adverse events associated with testosterone administration. N Engl J Med 2010; 363: 109-22.

[23] Dubois V, Laurent M, Boonen S, Vanderschueren D, Claessens F. Androgens and skeletal muscle: cellular and molecular action mechanisms underlying the anabolic actions. Cell Mol Life Sci 2012; 69: 1651-67.

[24] Chappard D, Chennebault A, Moreau M, Legrand E, Audran M, Basle MF. Texture analysis of X-ray radiographs is a more reliable descriptor of bone loss than mineral content in a rat model of localized disuse induced by the Clostridium botulinum toxin. Bone $2001 ; 28: 72-9$.

[25] Warner SE, Sanford DA, Becker BA, Bain SD, Srinivasan S, Gross TS. Botox induced muscle paralysis rapidly degrades bone. Bone 2006; 38: 257-64.

[26] Aliprantis AO, Stolina M, Kostenuik PJ, Poliachik SL, Warner SE, Bain SD, Gross TS. Transient muscle paralysis degrades bone via rapid osteoclastogenesis. FASEB J 2012; 26: 1110-8.

[27] Grimston SK, Silva MJ, Civitelli R. Bone loss after temporarily induced muscle paralysis by Botox is not fully recovered after 12 weeks. Ann N Y Acad Sci 2007; 1116: 444-60.

[28] Manske SL, Boyd SK, Zernicke RF. Vertical ground reaction forces diminish in mice after botulinum toxin injection. J Biomech 2011; 44: 637-43.

[29] Warden SJ, Galley MR, Richard JS, George LA, Dirks RC, Guildenbecher EA, Judd AM, Robling AG, Fuchs RK. Reduced gravitational loading does not account for the skeletal effect of botulinum toxin-induced muscle inhibition suggesting a direct effect of muscle on bone. Bone 2013; 54: 98-105.

[30] Ausk BJ, Huber P, Poliachik SL, Bain SD, Srinivasan S, Gross TS. Cortical bone resorption following muscle paralysis is spatially heterogeneous. Bone 2012; 50: 14-22.

[31] Bouvard B, Mabilleau G, Legrand E, Audran M, Chappard D. Micro and macroarchitectural changes at the tibia after botulinum toxin injection in the growing rat. Bone 2012; 50: 858-64.

[32] Ausk BJ, Huber P, Srinivasan S, Bain SD, Kwon RY, McNamara EA, Poliachik SL, Sybrowsky $\mathrm{CL}$, Gross TS. Metaphyseal and diaphyseal bone loss in the tibia following transient muscle paralysis are spatiotemporally distinct resorption events. Bone 2013; 57: 413-22.

[33] Cardozo CP, Qin W, Peng Y, Liu X, Wu Y, Pan J, Bauman WA, Zaidi M, Sun L. Nandrolone slows hindlimb bone loss in a rat model of bone loss due to denervation. Ann N Y Acad Sci 2010; 1192: 303-6. 
[34] Blouin S, Gallois Y, Moreau MF, Basle MF, Chappard D. Disuse and orchidectomy have additional effects on bone loss in the aged male rat. Osteoporos Int 2007; 18: 85-92.

[35] Libouban H, Blouin S, Moreau MF, Basle MF, Audran M, Chappard D. Effects of risedronate in a rat model of osteopenia due to orchidectomy and disuse: densitometric, histomorphometric and microtomographic studies. Micron 2008; 39: 998-1007.

[36] Yarrow JF, Ye F, Balaez A, Mantione JM, Otzel DM, Chen C, Beggs LA, Baligand C, Keener JE, Lim W, Vohra RS, Batra A, Borst SE, Bose PK, Thompson FJ, Vandenborne K. Bone loss in a new rodent model combining spinal cord injury and cast immobilization. J Musculoskelet Neuronal Interact 2014; 14: 255-66.

[37] Callewaert F, Bakker A, Schrooten J, Van Meerbeek B, Verhoeven G, Boonen S, Vanderschueren D. Androgen receptor disruption increases the osteogenic response to mechanical loading in male mice. J Bone Miner Res 2010; 25: 124-31.

[38] Sinnesael M, Laurent MR, Jardi F, Dubois V, Deboel L, Delisser P, Behets GJ, D'Haese PC, Carmeliet G, Claessens F, Vanderschueren D. Androgens inhibit the osteogenic response to mechanical loading in adult male mice. Endocrinology 2015; 156: 1343-53.

[39] De Gendt K, Swinnen JV, Saunders PT, Schoonjans L, Dewerchin M, Devos A, Tan K, Atanassova N, Claessens F, Lecureuil C, Heyns W, Carmeliet P, Guillou F, Sharpe RM, Verhoeven G. A Sertoli cell-selective knockout of the androgen receptor causes spermatogenic arrest in meiosis. Proc Natl Acad Sci U S A 2004; 101: 1327-32.

[40] Dubois V, Laurent MR, Sinnesael M, Cielen N, Helsen C, Clinckemalie L, Spans L, GayanRamirez G, Deldicque L, Hespel P, Carmeliet G, Vanderschueren D, Claessens F. A satellite cellspecific knockout of the androgen receptor reveals myostatin as a direct androgen target in skeletal muscle. FASEB J 2014; 28: 2979-2994.

[41] Dubois V, Simitsidellis I, Laurent MR, Jardi F, Saunders PT, Vanderschueren D, Claessens F. Enobosarm (GTx-024) Modulates Adult Skeletal Muscle Mass Independently of the Androgen Receptor in the Satellite Cell Lineage. Endocrinology 2015; 156: 4522-33.

[42] Grimston SK, Goldberg DB, Watkins M, Brodt MD, Silva MJ, Civitelli R. Connexin43 deficiency reduces the sensitivity of cortical bone to the effects of muscle paralysis. J Bone Miner Res $2011 ; 26$ : 2151-60. 
[43] Ophoff J, Van Proeyen K, Callewaert F, De Gendt K, De Bock K, Vanden Bosch A, Verhoeven G, Hespel P, Vanderschueren D. Androgen signaling in myocytes contributes to the maintenance of muscle mass and fiber type regulation but not to muscle strength or fatigue. Endocrinology 2009; 150: 3558-66.

[44] Laperre K, Depypere M, van Gastel N, Torrekens S, Moermans K, Bogaerts R, Maes F, Carmeliet G. Development of micro-CT protocols for in vivo follow-up of mouse bone architecture without major radiation side effects. Bone 2011; 49: 613-22.

[45] Maes C, Coenegrachts L, Stockmans I, Daci E, Luttun A, Petryk A, Gopalakrishnan R, Moermans K, Smets N, Verfaillie CM, Carmeliet P, Bouillon R, Carmeliet G. Placental growth factor mediates mesenchymal cell development, cartilage turnover, and bone remodeling during fracture repair. J Clin Invest 2006; 116: 1230-42.

[46] Masuyama R, Stockmans I, Torrekens S, Van Looveren R, Maes C, Carmeliet P, Bouillon R, Carmeliet G. Vitamin D receptor in chondrocytes promotes osteoclastogenesis and regulates FGF23 production in osteoblasts. J Clin Invest 2006; 116: 3150-9.

[47] Verhaeghe J, Van Herck E, Van Bree R, Van Assche FA, Bouillon R. Osteocalcin during the reproductive cycle in normal and diabetic rats. J Endocrinol 1989; 120: 143-51.

[48] Saita Y, Nakamura T, Mizoguchi F, Nakashima K, Hemmi H, Hayata T, Ezura Y, Kurosawa H, Kato S, Noda M. Combinatory effects of androgen receptor deficiency and hind limb unloading on bone. Horm Metab Res 2009; 41: 822-8.

[49] Weinstein RS, Jilka RL, Parfitt AM, Manolagas SC. The effects of androgen deficiency on murine bone remodeling and bone mineral density are mediated via cells of the osteoblastic lineage. Endocrinology 1997; 138: 4013-21.

[50] Manolagas SC. Steroids and osteoporosis: the quest for mechanisms. J Clin Invest 2013; 123 : 1919-21.

[51] Almeida M, lyer S, Martin-Millan M, Bartell SM, Han L, Ambrogini E, Onal M, Xiong J, Weinstein RS, Jilka RL, O'Brien CA, Manolagas SC. Estrogen receptor-alpha signaling in osteoblast progenitors stimulates cortical bone accrual. J Clin Invest 2013; 123: 394-404.

[52] Zhao J, Zhang Y, Zhao W, Wu Y, Pan J, Bauman WA, Cardozo C. Effects of nandrolone on denervation atrophy depend upon time after nerve transection. Muscle Nerve 2008; 37: 42-9. 
[53] Camerino GM, Desaphy JF, De Bellis M, Capogrosso RF, Cozzoli A, Dinardo MM, Caloiero R, Musaraj K, Fonzino A, Conte E, Jagerschmidt C, Namour F, Liantonio A, De Luca A, Conte Camerino D, Pierno S. Effects of Nandrolone in the Counteraction of Skeletal Muscle Atrophy in a Mouse Model of Muscle Disuse: Molecular Biology and Functional Evaluation. PLoS One 2015; 10: e0129686.

[54] Kvorning T, Christensen LL, Madsen K, Nielsen JL, Gejl KD, Brixen K, Andersen M. Mechanical muscle function and lean body mass during supervised strength training and testosterone therapy in aging men with low-normal testosterone levels. J Am Geriatr Soc 2013; 61: 957-62.

[55] Saxon LK, Galea G, Meakin L, Price J, Lanyon LE. Estrogen receptors alpha and beta have different gender-dependent effects on the adaptive responses to load bearing in cancellous and cortical bone. Endocrinology 2012; 153: 2254-66.

[56] Windahl SH, Saxon L, Borjesson AE, Lagerquist MK, Frenkel B, Henning P, Lerner UH, Galea GL, Meakin LB, Engdahl C, Sjogren K, Antal MC, Krust A, Chambon P, Lanyon LE, Price JS, Ohlsson C. Estrogen receptor-alpha is required for the osteogenic response to mechanical loading in a ligandindependent manner involving its activation function 1 but not 2. J Bone Miner Res 2013; 28: 291-301. [57] Klein-Nulend J, Bakker AD, Bacabac RG, Vatsa A, Weinbaum S. Mechanosensation and transduction in osteocytes. Bone 2013; 54: 182-90.

[58] Windahl SH, Börjesson AE, Farman HH, Engdahl C, Movérare-Skrtic S, Sjögren K, Lagerquist MK, Kindblom JM, Koskela A, Tuukkanen J, Divieti Pajevic P, Feng JQ, Dahlman-Wright K, Antonson P, Gustafsson JÅ, Ohlsson C. Estrogen receptor-alpha in osteocytes is important for trabecular bone formation in male mice. Proc Natl Acad Sci U S A 2013; 110: 2294-9.

[59] Melville KM, Kelly NH, Surita G, Buchalter DB, Schimenti JC, Main RP, Ross FP, van der Meulen M. Effects of Deletion of ERalpha in Osteoblast-Lineage Cells on Bone Mass and Adaptation to Mechanical Loading Differ in Female and Male Mice. J Bone Miner Res 2015; 30: 1468-80.

[60] Ellman R, Spatz J, Cloutier A, Palme R, Christiansen BA, Bouxsein ML. Partial reductions in mechanical loading yield proportional changes in bone density, bone architecture, and muscle mass. J Bone Miner Res 2013; 28: 875-85. 